\title{
Design and Implementation of a $\mathrm{HCl}$ Course for MIS Students - Some Lessons
}

\author{
Rachel Or-Bach \\ The Max Stern Yezreel Valley College, Israel
}

orbach@yvc.ac.il

\begin{abstract}
Courses on Human Computer Interaction (HCI) largely differ in the conception of the role of the course in the program, in the topics to be included, in emphases, in the instructional strategies that are employed, and more. This paper describes the design and implementation of a HCI course for students of the Management Information Systems department in our college. Students' intermediate and final homework assignments were analyzed to provide feedback for the course design. Quantitative analysis showed high correlation between the quality of the requirement analysis performed by the students and the quality of the final interface prototype, and also that the quality of design alternatives that were considered by the students can be a good predictor for the quality of the overall interface design. Qualitative analysis of students' submissions showed the need for practicing skills required in users' studies, especially conducting interviews and observations. Implications from these and other findings are discussed.
\end{abstract}

Keywords: Human computer interaction, User centered design, Studio-based learning, Alternative designs, Design tradeoffs, Prototyping

\section{Introduction}

Courses on Human Computer Interaction (HCI) in Computer Science, in Information Systems and in other Information Technology departments largely differ in topics to be included, emphases, instructional strategies that are employed, and more. The differences do not necessarily depend on the type of the department (e.g., Computer Science versus Management Information Systems) but on the way the instructor (or the faculty) perceives the role of such a course in the curriculum as well as the role of HCI in a system development cycle. The perception of the role of the HCI course directs the emphases to be addressed in the course. The instructional strategies that are employed in such a course are usually derived from the above as well as from the instructor's learning and teaching philosophy.

Material published as part of this publication, either on-line or in print, is copyrighted by the Informing Science Institute. Permission to make digital or paper copy of part or all of these works for personal or classroom use is granted without fee provided that the copies are not made or distributed for profit or commercial advantage AND that copies 1) bear this notice in full and 2) give the full citation on the first page. It is permissible to abstract these works so long as credit is given. To copy in all other cases or to republish or to post on a server or to redistribute to lists requires specific permission and payment of a fee. Contact Publisher@,InformingScience.org to request redistribution permission.
It is widely recognized that the user interface is of major importance in any software project. The estimation is that at least $50 \%$ of work on a software project goes into the design and implementation of the user interface (Daniel et al., 2007; Kennard \& Leaney, 2010). In today's world of fast development and deployment of technology, HCI factors are even more critical and fundamental and, thus, should be well addressed in 
the curriculum (Douglas, Tremaine, Leventhal, Wills, \& Manaris, 2002; Peslak, 2005). Carey et al. (2004) stress the role of human-computer interaction in Management Information Systems (MIS) curricula and differentiate between CHI (Computer Human Interaction) and HCI to indicate the different points of view (computer versus human). The importance of HCI in MIS education will be further discussed in the next section.

Homework assignments that are given during a course, whether for formative or summative assessment, provide indicators for students about the relative importance of the different topics or concepts involved in the course. Shepard (2000), in a paper titled "The Role of Assessment in a Learning Culture", stresses the need to design assessments that match the subject matter standards and serve to instantiate what it means to know and learn in each discipline. Besides the content, the instructional method that is employed to support learning in a course might also provide a model for preferred processes regarding the implementation of the learned materials. The learning process that an instructional method models and promotes can provide a foundation on which a lifetime of learning in work and other social settings can be built (Boud \& Falchikov, 2006). The design of the assessment assignments in the course that is described in this paper followed these ideas. The assignments were planned to focus on the main concepts and procedures for designing an interface along with team work that characterizes the respective work culture. The formative evaluation study described in this paper examines how the emphases of the course that are reflected in the course assignments (content and respective pedagogy) relate to the students' final submitted project. The final project included an interface prototype, description of design considerations, and description of the interface evaluation.

The remainder of this paper is organized as follows. The second section reviews curricular approaches and instructional strategies for a HCI course instruction. The third section describes the main characteristics of our HCI course, including a detailed description of each of the course assignments. The fourth section, with its subsections, describes the goals of the study, the tools, and the findings of the study. The fifth section summarizes the findings and discusses the key results.

\section{$\mathrm{HCl}$ Instruction - Curricular Approaches and Instructional Strategies}

Human-Computer Interaction design is interdisciplinary in nature and is studied and taught by researchers, educators, and practitioners from disciplines such as computer science, psychology, management information systems, information science, and human factors engineering. HCI goals include ensuring system functionality and usability, providing effective user interaction support, and enhancing a pleasant user experience (Carey et al., 2004). Winograd (1990) suggested for the new (then) domain of human-computer interaction to include in computer science curricula a course in human-computer interaction to "shift the center" of computer science and to understand and design systems for real users. He claimed that students need to develop competency in understanding and devising user friendly systems and solutions through "guided learning". Since then, and even though there is a general agreement on the importance of thoroughly thinking about (and "testing") the users' expected interactions, whether and how to include and design a course on human-computer interaction still remain a debated issue.

Carey et al. (2004), in a call for action that stresses the role of HCI in the Management Information Systems (MIS) curriculum, use the term HCI to represent the MIS-based human computer interaction focus and the term CHI to represent the Computer Science-based computer human interaction focus. They make the case that HCI is an integral part of MIS, citing Ahituv and Neumann's (1986) definition of MIS as "the systematic study of information systems. An information system is a set of components (people, hardware, software, data, and procedures) that operate together to produce information that supports the operation and management functions of an 
organization." The MIS orientation has a broad systems orientation, and thus HCI studies in MIS are concerned with the ways humans interact with information, technologies, and tasks, especially in business, managerial, organizational, and cultural contexts (Zhang et al. 2002). Carey et al. (2004) stress also the importance of HCI in modern systems development as programmers and analysts now spend much more time interacting with each other and interacting with users to determine informational and decision making needs along with getting feedback during development iterations. Focusing attention on HCI issues should result in IS professionals who will pay attention and understand human needs and thereby enhance communication between themselves and the users. The above mentioned call for action presents several strategies and options for the integration of HCI into current and future MIS courses along with pedagogical suggestions for teaching HCI to undergraduate and graduate students. The emphasis they suggest for teaching undergraduate students is on class time, basic concepts and principles, and hands-on experiences.

Peslak (2005) reviewed the literature in all areas of computing and information systems and sciences to define interface topics that are generally regarded as most important for technology students. He identified twelve specific topic areas that relate to the two major subcategories of HCI People and Processes. The specific topics are Interface Requirements, Interface and GUI (Graphical User Interface) Design, Interface Analysis, Assessment and Evaluation, Design Psychology, Human Behavior and Abilities, Implementation, Collaboration, Communications and Teamwork, Costs/Benefits, Testing, Prototyping, and Disability. Churchill, Bowser, and Preece (2013) report on an ongoing project sponsored by the ACM SIGCHI Executive Committee to investigate the philosophies and practices that underpin present and future HCI education. They conducted surveys and interviews in more than 30 countries and found that many participants identified interdisciplinarity as a key element in HCI education. Even though they addressed HCI education as a whole program and not only a course (or a small set of courses), their findings show the same tensions that we encountered related to the relative emphasis on technical skill sets (especially the role of programming) and the tension related to theory versus practice in HCI education.

Carey et al. (2004) suggest three options for incorporating HCI materials into IS curricula: (1) integrate with core business major IS courses, (2) integrate with required IS courses, and (3) offer a separate HCI course. We chose a separate course as it seems more suitable for discussing and practicing the whole interface design process, and as from a practical point of view it is easier to administer a separate course.

Zhang (2003) suggested instructional techniques for a HCI course that include in-class exercises $\&$ discussions, readings, case studies, a design or usability evaluation project (group based), short essays to justify a (good) design decision or criticize a (bad) design example, peer evaluation of other groups' projects, and class presentations. Draganova and Doran (2013) suggested various tailored pedagogical approaches for teaching HCI in undergraduate IT programs that are similar to the above but include also class and online discussions; case studies; and participation in HCI research methods experiments and work. The studio-based instructional approach, discussed later in this section, provides an opportunity for integrating several of the above approaches.

The need for providing some actual experience with human-computer interaction design in a HCI course is widely advocated. It goes well with the current instructional approaches of active learning. Active learning is generally defined as any instructional method that engages students in the learning process. Active learning requires students to do meaningful learning activities and think about what they are doing (Bonwell \& Eison, 1991). Peslak (2005) developed, implemented, and evaluated hands-on activities to have students experience the main concepts of human computer interaction design such as expert elicitation, creative (out-of-the-box) design, design for disability, and interface evaluation. The assignments we have designed have similar goals, but for our assignments each team concentrated during the course on the design of only one interface that was gradually and iteratively modified and improved during the semester as the topics and the 
respective understanding evolved. The reason for this choice was that the integration of all the topics seemed important along with the opportunity for the students to invest more time and to rethink of the different (but related) topics manifested in the same interface. Focusing on one interface helps to emphasize the process facet of the design and the need to consider use cases or scenarios.

Scenario-based design is a family of techniques in which the use of a future system is concretely described at an early point in the development process. Narrative descriptions of envisioned usage episodes are then employed in a variety of ways to guide the development of the system that will enable these use experiences (Rosson \& Carrol, 2002). Carrol (1999) suggested five reasons for scenario-based design of information systems, reasons that we found useful to stress for our HCI course: (1) Scenarios evoke reflection, helping developers coordinate design action and reflection; (2) Scenarios are at once concrete and flexible, helping developers manage the fluidity of design situations; (3) Scenarios afford multiple views of an interaction and diverse kinds and amounts of detailing, helping developers manage the many consequences entailed by any given design move; (4) Scenarios can also be abstracted and categorized, helping designers to recognize, capture, and reuse generalizations; (5) Scenarios promote work-oriented communication among stakeholders, helping to make design activities more accessible to great variety of expertise.

In design-oriented programs (e.g., arts, industrial design, and architecture) it is common to use a studio-based instructional approach. It involves a shared space where students work iteratively on assigned design projects, periodically presenting their work to their peers and instructor for critical review and feedback. Several computing educators have explored the use of studio-based learning in their courses (e.g., Hundhausen, Agrawal, Fairbrother \& Trevisan, 2010; Myneni, Ross, Hendrix, \& Narayanan, 2008). Because of its focus on design, a HCI course seems a good candidate for studio-based instruction (e.g., Hundhausen, Fairbrother, \& Petre, 2011; Reimer \& Douglas, 2003). Greenberg (2009) described his experience and respective suggestions from embedding a design studio course of HCI in a conventional Computer Science program. With the studio-based approach students are required to sketch out their ideas and publicly show these sketches to other classmates for critique. Students also share tricks and techniques, and they engage in on-going commentaries. These characteristics of a studio approach were incorporated in our course, even though the course was not entirely studio-based. The course suggested by Greenberg (2009) was a second course on HCI, so it was appropriate to focus more on specific kinds of interaction technologies, while our course is the first and only HCI course in the MIS curricula, so it still contained lectures and the actual experiences focused more on considering the users during the design process than on different interaction technologies.

\section{The $\mathrm{HCl}$ Course - Main Characteristics}

The course on Human Computer Interaction is a mandatory course in our undergraduate program of the Management Information Systems department. It is provided in the second semester of the second year, after the students have had several programming courses and completed a course on Systems Analysis and Design. During the third (last) year these students are expected to design and implement an information system of their choice. One of the goals of our HCI course is to foster the role of the interaction design in the overall system development cycle. The emphasis on the users and on the major role of use cases (or scenarios) are expected to illuminate the interrelationships between the interaction design and the design of the other elements of the system that should enable these interactions. Zhang, Carey, Te'eni, and Tremaine (2005) claim that incorporating a HCI perspective into the systems development life cycle is critical to information systems success and in turn to the success of businesses. A focal point of our HCI course is a capstone 
user interface design project to be carried out in small teams. This final project gives students the opportunity to experience and exercise the principles and ideas they learn about in the course.

Our HCI course was administered in a computer lab in order to enable hands-on exercises of examination of various design examples. The examples were chosen to trigger thought and discussions about design principles. The computer lab setting enables studio-type sessions in which theory and practice can be better integrated. The course consisted of 13 sessions, each lasting 3 hours. Most of the sessions were a combination of lecture, demonstration, and hands-on activities. About three sessions were devoted to teams' presentations with follow-up discussions.

For the various levels of the design (conceptual, layout, and screen elements), the issues of designing alternatives and thinking about trade-offs were strongly stressed during the course.

From the beginning of the course students were presented with an introduction to the course homework assignments that were steps and partial drafts to guide the final assignment/project. The idea was to have students experience the design process while having a specific goal for which the learned ideas can be applied gradually and iteratively. Students had to form teams of 23 students and choose a topic for an information system that can have a "rich" set of interactions that have also some "depth" (series of interaction steps depending on the user inputs). Additional requirement for the choice of a topic was that the students have access to potential users of such a system. The teams and the topic could not be changed after the first assignment, unless the topic was not appropriate for demonstrating interaction design. The requirement of working in a team was strict in order to promote an exchange and mutual evaluation of ideas during all the design phases. For each assignment students were required to prepare materials both for the instructor (with more details and explanations for the rational of choices, etc.) and materials for class presentation. The class presentations were conducted in a studio-type approach with the aim to get feedback and suggestions from classmates, to share ideas, to communicate design principles, and to be exposed to the work of the other teams. Students were provided with detailed explanations about the type of topic to choose (interactivity requirements and availability of potential users), the role of class presentations, the importance of continuous communication with potential users, the practice of ongoing revisions, and the need to think about design alternatives and tradeoffs. The first assignment dealt with needs (requirements) assessment and with task analysis. The second assignment dealt with conceptual design, design in several levels, and design of alternatives. For the third and final assignment students were required to submit an implemented interface that demonstrates the interaction capabilities for 3 meaningful predefined use cases/scripts of their choice. A more detailed description of each of the course assignment follows for better understanding the study findings that are based on the analysis of the submitted assignments.

\section{The first assignment}

The first assignment dealt with needs assessment and task analysis and students were required to:

1. Explain the system for which they are going to design an interface, addressing specifically goals, existing similar systems, and types of potential users.

2. Conduct and report the details of interviews (or surveys) with potential users; including the interview skeleton that was prepared, other artefacts that were used during the interview, the implementation and the results.

3. Based on the above, provide detailed expected use cases.

\section{The second assignment}

In the second assignment students were required to design the overall conceptualization along with at least five more specific interaction design examples. The goal for the second assignment was to have students think about alternatives and make explicit what design principles are addressed, how it is related to the users' goals, and what were the relevant tradeoffs when choosing between alternatives. 
For each example students had to explain the following issues:

1. Context of the example

2. The guiding design principles

3. Alternatives that were considered, what the guiding design principles for these alternatives were, and what the reasons for the preferred design were.

The third/final assignment

For the final assignment students were required to submit the interface as a SketchFlow project that runs for at least three meaningful predefined use cases that they chose for demonstrating the interaction capabilities (including ways to show affordances, different feedback options, help, etc.)

Besides the software students were required to submit a document that includes the following:

1. General description of the system for which the interface was designed (goals, potential users, similar existing systems, etc.)

2. Description of the chosen use cases with emphasis on the user specific goal and then a detailed description of all the steps the user should do (including help he/she can get, feedback (for correct and incorrect actions) etc.

3. Explanation about additional procedures and data that the system should use (besides user inputs) in order to provide feedback and adapt the interface.

4. Detailed reports of the evaluation procedures that were conducted with the implemented interface (and the specific use cases); both expert evaluation (using cognitive walkthrough) and evaluation by users (interviews and observations with think aloud request). The reports were supposed to include the evaluation process, results and recommendations as derived from the results.

\section{Study Goals, Tools, and Findings}

\section{Goals, Tools, and Procedures}

The goal of the study was to investigate how the course special characteristics and particularly the thoughtful design of the students' homework assignments were reflected in the quality of the students' final work. The quality of the students' final work means the quality of the interface along with the explicit required explanations. The study was a formative evaluation study. Formative evaluation is intended to foster development and improvement within an ongoing activity (or person, product, program, etc.), in contrast to summative evaluation where the activity is assessed at the end of an operating cycle for decisions on adoption, continuation, etc. Thus the formative evaluation of this study was intended for improving the HCI course. The focus of our formative evaluation study was on the students' assessment tools - the homework assignments - and their guidance role.

We chose to use unobtrusive measures and thus the students' submitted assignments served as the main research tool. A special coding and scoring scheme was developed for each of the assignments. For evaluating the guidance role of the intermediate assessment tools we concentrated on two emphases of the course: user-centered design and considerations of design alternatives. The first emphasis was strongly reflected in the first assignment, while the second emphasis was strongly reflected in the second assignment. Each of the intermediate assignments dealt with a different aspect of the interface design process, so we were interested in finding out the relation between these intermediate design steps to the final interface as this might demonstrate required emphases for the course. We used statistical methods for examining the relation of the quality of the intermediate assignments to the quality of the final submitted interface design. The students' description of the evaluation that they performed to the interface that they had designed served as 
an additional focus for our formative evaluation study. The description of the interface evaluation by users seems to be informative of the students' approach to users' studies as well as to the interaction facilities of the interface. The content analysis of this part of the students' submitted document was used for the respective qualitative facet of the study. The interface evaluation quality should indicate the importance students assign to the evaluation and might indicate the finegrained considerations taken into account in the design. The students' reports were categorized and ranked by the quality of the observation report, by the quality of the interviewing process and by the summary of findings and recommendations.

Sixteen teams of 2-3 students participated in the study. One additional team was excluded from the study because the students were repeating the course and the assignments were modified for them.

\section{Findings}

The findings described in this section are based mainly on students' submitted assignments. Some additional general findings that are presented here are based on the instructor's (the paper author) impressions during the course.

The general quality of the user interface design project (the final assignment) was good. The average score was 82.0 (out of 100) with 16.6 SD.

The correlation between the scores of the first assignment, dealing with requirements analysis, and the scores of the final assignment was calculated using Pearson Product-Moment Correlation Coefficient. The same statistical analysis was conducted for the second assignment, dealing with design alternatives and the scores of the final assignment. A statistically significant relationship was found between the first assignment and the final assignment, $r(14)=.81, p<.05$. A statistically significant relationship was also found between the second assignment and the final assignment, $r(14)=.60, p<.05$. The higher correlation with the first assignment might indicate the importance of understanding and considering the users from the beginning of the design process. Teams that invested more effort in understanding the requirements and producing respective use cases generated a better final project (the interface and the accompanying required document).

Figure 1 presents a diagram that relates the quality of "alternatives' consideration" for the design to the final assignment's score. The quality of the design of alternatives in the second assignment was rated for each team on a scale of 3 , where 3 was the top score.

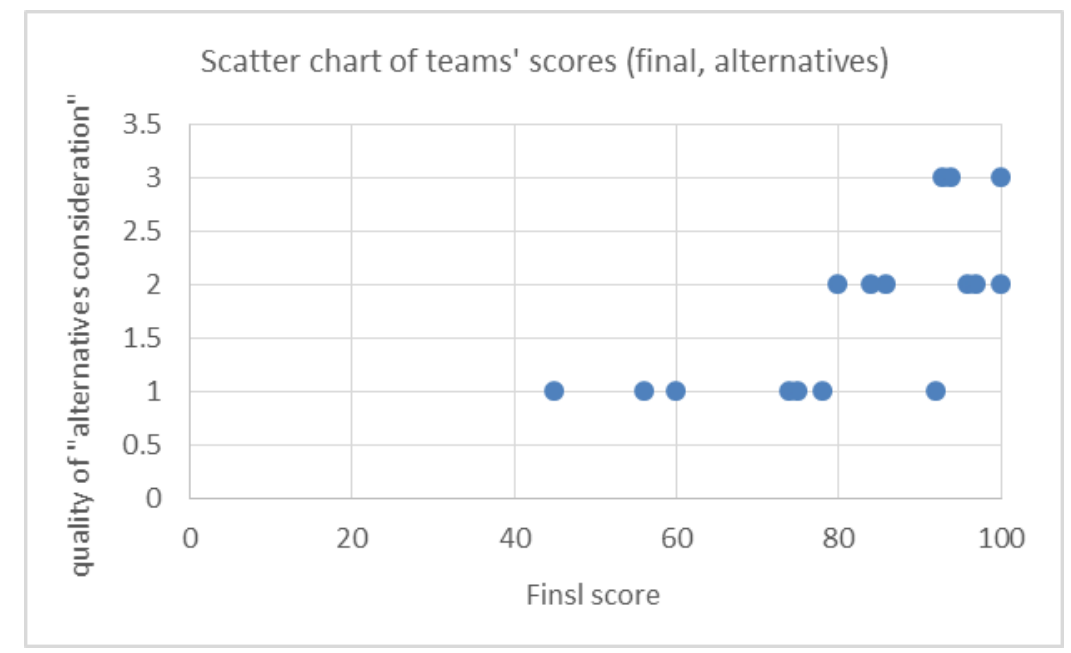

Figure 1: The relation between the quality of "alternatives' consideration" to the final project score 
Figure 1 shows that the quality of design alternatives can be a good predictor for the overall design of the interface, and thus the emphasis on producing design alternatives is important. Teams with low quality of alternative designs in the second assignment probably haven't repeated this stage and thus ended up with a low quality final work.

As was explained in the previous section on the study tools and procedures, content analysis was conducted for the interface evaluation that students performed and reported about. The reports were categorized and ranked by the quality of the observation report, by the interviewing process, and by the summary of findings and recommendations. It was interesting to see that students followed different patterns with regard to the evaluation. For some the interview played a bigger role, while for others the observation. But only a third of the teams were able to provide a detailed and meaningful report of their users' observation. It seems that it was not easy for the students to conduct an observation with minimal interventions. Many observation reports were more similar to a structured interview. The interface formative evaluation that was required in the final assignment might be indicative of the way students see the iterative nature of design as well as the role of the interface and the interaction design in the whole process of a system design. For most of the teams the evaluation report (looking mainly at the evaluation by users) was with a prescriptive point of view. The report described details in the context of what should be done with it (save, modify, add, etc.). Only a few reports demonstrated a descriptive point of view, clearly distinguishing between what was observed and the interpretation that might lead to any modification.

There were some difficulties that students had that were observed in the submitted assignments. Producing good design alternatives was not easy for the students. No doubt it is not easy for any designer but gets easier with experience. Some suggested alternatives were of clearly "bad design", where the better one is obvious and not an adequate alternative design. Another difficulty students had, as observed in their reports, was to define the relevant design principles they employed (or tried to employ). Students stated more general principles instead of trying to refine, be precise, and clearly distinguish between sub-categories of design principles.

The in-class presentations and peer critique seem to be less effective than expected. The instructor impression was that it was very beneficial for the teams to prepare the presentation and was beneficial for other teams to see different ideas. The critique and improvement suggestions were not productive enough. Students were very careful not to critique or make suggestions that might sound as critique. This studio-type culture of productive feedback requires training and practice for a longer period to be effectively developed.

\section{Summary and Discussion}

The HCI course for the MIS students emphasized the following issues for interaction design: user-centered design, scenario-driven design, and considerations of design alternatives and tradeoffs; and a studio-type approach that involves sharing ideas and peers' critiques.

The relative higher correlation that was found between the score of the first assignment and the final product fosters the relative importance of both the user-centered and the scenario-driven approaches for effective HCI design. It might be instructionally beneficial to present these findings to the next year students for motivating them to invest more effort in the first assignment that might greatly influence the resulted interface. It is important to stress the consideration of the users again and again during the course. Looking at the submitted reports for the first homework assignment it became clear that students need more training in extracting relevant data from potential users. This might involve practicing interview techniques as well as initial preparation of artefacts (paper-based or computer-based) to elicit expectations, requirements, and preferences from potential users. 
Findings also showed that thoughtful consideration of alternatives is a good predictor for the quality of the overall product. Those that did not do it thoughtfully were those that got the worst scores for the final assignment. This also can be instructionally effective to show to students, as it may be more convincing than the commonly cited phrase that generating a multitude of designs is the best way to produce a good design. As was mentioned earlier, students found it difficult to produce alternative designs. It requires more time with several iterations of feedback and improvements, which is challenging to implement in a one semester course. Greenberg (2009), for example, stressed the requirement from students to generate many different sketches for demonstrating quite different ideas and then refine and choose the most appropriate one. The course described by Greenberg (2009) is the second course on HCI (for CS students), thus making it easier to spend more time on design ideas, feedback, and iterations.

The students' submissions showed the need for more training of skills that are regularly involved in users' studies, especially for conducting interviews and observations. Such skills are important for defining or refining requirements and for the ongoing evaluation of the interface design. Information Systems students usually don't have opportunities to learn and practice these skills which are necessary for information systems design. Tay (2012) argues that IS students in both Systems and Analysis Design and Human Computer Interaction courses are ill-equipped to utilize qualitative methods to gather and analyze users' requirements. He stresses the need for qualitative methods in undergraduate IS education. Similarly, Weinberg and Stephen (2002) recommend teaching ethnography methods to computer scientists. As was mentioned in the findings section, students found it difficult to observe and describe the observation without suggesting modifications adapted to their initial conceptions. This prescriptive point of view can be easily translated to recommendations but might limit the information that can be obtained with a more open, descriptive, ethnographic-like approach.

The "Prototype Walkthrough" (PW) studio-based learning activity for HCI courses (Hundhausen et al., 2011) might be a good way to refine our assignments. With the PW activity a student project team simulates its evolving user interface prototype while a student audience member acts as a test user. Classmates are encouraged to ask questions and provide feedback. PW fosters a scenario-based design that considers the users seriously. Having one of the students as a test user might encourage active participation and enable more critiques along with constructive feedback. The PW activity as a studio-based learning activity can also be used for considering alternative designs, an important emphasis in our course.

\section{References}

Ahituv, N., \& Neumann, S. (1986). Principles of Information Systems for Management, Dubuque, IA: William C. Brown.

Bonwell, C. C., \& Eison, J. A. (1991). Active learning: Creating excitement in the classroom. ASHEERIC Higher Education Report No.1, George Washington University, Washington, DC.

Boud, D., \& Falchikov, N. (2006). Aligning assessment with long-term learning, Assessment and Evaluation in Higher Education, 31(4), 399-413.

Carey, J., Galleta, D., Kim, J., Te'eni, D., Wildemuth, B., \& Zhang, P. (2004). The role of humancomputer interaction in the MIS curriculum: A call to action. Communications of the Association for Information Systems, 13, 357-379.

Carroll, J. M. (1999). Five reasons for scenario-based design. Proceedings of the 32nd Hawaii International Conference on Systems Sciences, Wailea, HI.

Churchill, E., Bowser, A., \& Preece, J. (2013). Teaching and learning human-computer interaction. Retrieved from http://interactions.acm.org/archive/view/march-april-2013/teaching-and-learning-humancomputer-interaction 
Daniel, F., Matera, M., Yu, J., Benatallah, B., Saint-Paul, R., \& Casati, F. (2007). Understanding UI integration: A survey of problems, technologies, and opportunities. IEEE Internet Computing 11(3), 5966.

Draganova, A., \& Doran, P. (2013). Use of HCI components into IT courses. International Journal of Information and Education Technology, 3(2), 245-248.

Douglas, S., Tremaine, M., Leventhal, L., Wills, C., \& Manaris, B. (2002). Incorporating human-computer interaction into the undergraduate computer science curriculum. Proceedings of the 33th SIGCSE Technical Symposium on Computer Science Education, 211-212.

Greenberg, S. (2009). Embedding a design studio course in a conventional computer science program. In: P. Kotze, W. Wong, J. Jorge, A. Dix, \& S. P. Alexandra (Eds.), Creativity and HCI: From experience to design in education (pp. 23-41). Springer.

Hundhausen, C., Agrawal, A., Fairbrother, D., \& Trevisan, M. (2010). Does studio-based instruction work in CS1? An empirical comparison with a traditional approach. In SIGCSE '10, Milwaukee, Wisconsin, USA.

Hundhausen, C. D., Fairbrother, D., \& Petre, M. (2011). The "prototype walkthrough": A studio-based learning activity for human-computer interaction courses. ICER'11, August 8-9, 2011, Providence, Rhode Island, USA.

Kennard, R., \& Leaney, J. (2010). Towards a general purpose architecture for UI generation, Journal of Systems and Software, 83(10), 1896-1906.

Myneni, L., Ross, M., Hendrix, D., \& Narayanan, N. (2008). Studio-based learning in CS2: An experience report. In Proceedings of the 46th ACM southeast conference (ACM-SE 2008), 253-255. ACM Press, New York.

Peslak, A. (2005). A framework and implementation of user interface and human-computer interaction instruction. Journal of Information Technology Education, 4, 189-205. Retrieved from http://www.jite.org/documents/Vol4/v4p189-205Peslak38.pdf

Reimer, Y., \& Douglas, S. (2003). Teaching HCI design with the studio approach. Computer Science Education, 13(3), 191-205.

Rosson, M. B., \& Carrol, J. M. (2002). Scenario-based design. In J. Jacko \& A. Sears (Eds.), The humancomputer interaction handbook: Fundamentals, evolving technologies and emerging applications, Chapter 53. Lawrence Erlbaum Associates.

Shepard, L. A. (2000). The role of assessment in a learning culture. Education Researcher, 29(7), 4-14.

Tay, A. S. M. (2012). The need for qualitative methods in undergraduate IS education. Issues in Informing Science and Information Technology, 9, 105-114. Retrieved from http://iisit.org/Vol9/IISITv9p105114Tay116.pdf

Weinberg, J. B., \& Stephen, M. L. (2002). Participatory design in a human-computer interaction course: Teaching ethnography methods to computer scientists. In Proceedings of SIGCSE'02 (Computer Science Education), Covington, KY, USA, 237-241 ACM Press.

Winograd, T. (1990). What can we teach about human-computer interaction? Proceedings of the SIGCHI Conference on Human Factors in Computing Systems: Empowering People, 443-449.

Zhang, P. (2003). The role of HCI in the MIS curriculum. Proceedings of the Americas Conference on Information Systems, August, Tampa, FL. pp. 2080-2082. Also online at http://melody.syr.edu/hci/amcis03_t_panel/

Zhang, P., Benbasat, I., Carey, J. M., Davis, F., Galletta, D., \& Strong, D. (2002). Human computer interaction research in the MIS discipline. Communications of the Association of Information Systems, 9(20), 334-354.

Zhang, P., Carey, J., Te'eni, D., \& Tremaine, M. (2005). Integrating human-computer interaction development into the systems development life cycle: A methodology. Communications of AIS, 15, 512-543. 


\section{Biography}

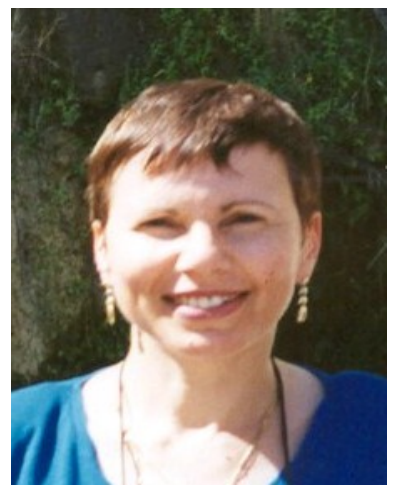

Rachel Or-Bach is a senior lecturer in the Management Information Systems department in the Max Stern Yezreel Valley College, Israel. She received her Ph.D. from the Technion-Israel Institute of Technology. Her main research interest is design of interactive learning environments. Her multidisciplinary research is published in journals of information technology for education, science education, computer science and information systems education, informing science, etc. 